\title{
ESENCIA Y PRÁCTICA DE LA HISTORIA ORAL
}

\author{
Pablo Pozzi*
}

\section{Resumen}

Este artículo/conferencia discute la relación entre historia, historia oral, y la historia del presente. Postula que escisión entre estas no es fija sino que se articulan entre sí hasta el punto que sus fronteras se desdibujan. Asimismo, a partir de plantear a la historia oral como una subrama de la ciencia histórica, se discute si las particularidades latinoamericanas pueden significar que existe una historia oral propiamente "latinoamericana".

Palabras clave: Historia. Oralidad. América Latina. Prácticas de historia.

Hace ya muchísimos años compartí una mesa redonda con un destacado historiador de Nigeria: Okun Udet Uya. Cuando dije que yo me dedicaba a la historia oral vi que se sonreía con picardía y le pregunté por qué. Me dijo que él no hacía historia oral y tampoco historia escrita ya que, como historiador y africano, sabía que era casi imposible "hacer historia” sólo con documentos. Su historia era, necesariamente, una historia llena de oralidad porque el colonialismo se había dedicado a eliminar los registros escritos de sociedades como, por ejemplo, Timbuktú o el Imperio de Mali. Me pareció interesante ya que el contraste entre historia oral e historia escrita es una construcción de la era de la modernidad.

Asimismo, el tema de la memoria y de los recuerdos históricos también se encuentra ligado e inficionado por pautas, tradiciones y patrones culturales de sociedades determinadas. Como bien señaló James K. Loewen (1996) sólo los occidentales dividimos a los seres humanos en vivos y muertos. Otras sociedades, como algunas africanas, los dividen en tres: los vivos, los sashas y los zamani. Los sashas no están enteramente muertos, porque viven en

\footnotetext{
* Professor da Universidad de Buenos Aires - Argentina. Diretor do Programa de História Oral da mesma universidade e Presidente da Asociación de Historia Oral de la República Argentina. E-mail: pablo@pozzi.satlink.net
} 
la memoria de aquellos que los conocieron, que los pueden recordar y evocar su fisonomía en arte, y traerlos al presente en anécdotas e historias. Cuando la última persona en haber conocido un ancestro muere, ese ancestro deja los sasha para convertirse en zamani, los muertos.

Tanto la apreciación de Okun Uya como la distinción en torno a los ancestros me parecen importantes para reflexionar sobre la historia oral en nuestras sociedades. Pero aún creo que las ramas y prácticas de la historia son realmente inescindibles y que hacen a la esencia histórica. Cuando me refiero a "esencia” lo hago pensando en los fines y objetivos de nuestra profesión. Tal como señaló E.H. Carr (1981, p. 34): “La función del historiador no es ni amar el pasado ni emanciparse de él, sino dominarlo y comprenderlo, como clave para la comprensión del presente”. O al decir de Lucién Febvre (1974, p. 21): es “una necesidad de la humanidad... que permite comprender el tiempo presente y vivirlo.” Así toda historia, y todo estudio histórico, remiten a una noción de presentismo y de historia reciente, más allá del tiempo cronológico que sea su eje de estudio.

El tema de la esencia y de la práctica de la historia es uno de los temas dejados de lado en la formación de nuestros estudiantes el día de hoy, pero era central hace ya treinta años. Si la historia es "el ser humano, en sociedad, a través del tiempo", entonces no hay realmente una esencia particular a la historia oral que la diferencie de la historia a secas. Es más, la historia oral sería una subrama de la historia, al igual que la historia económica, o la historia social, o la historia de género. Su especificidad se deriva de que el eje central de su estudio es la subjetividad humana como elemento determinante de prácticas y del quehacer. En otras palabras, para el historiador oral la subjetividad (como señaló Raymond Williams) es parte de lo material de la historia, al igual que lo pueden ser los datos económicos, los documentos policiales, o la prensa de masas.

Lo anterior me parece importante ya que pareciera existir una tendencia a subsumir enfoques antropológicos o sociológicos en la historia oral convirtiéndola en un híbrido marginado de todas las disciplinas. La oralidad es parte de numerosas disciplinas, pero la historia oral, por cuanto es historia, tiene las reglas y la cientificidad de la disciplina histórica. Yo me reivindico como un historiador que hace historia social e historia oral. No acepto que se me separe de la profesión y de sus criterios simplemente "por que sí”.

En los últimos diez años, Argentina ha atravesado un proceso de conflictos y reacomodamientos en más de un aspecto. Reclamos, protestas y resistencia se combinaron tanto en la búsqueda de nuevas formas de manifestación como en el rescate de caminos ya experimentados. Desde las ciencias sociales se buscó abarcar la multiplicidad del tema, 
actores y procesos que emergieron en la transición del neoliberalismo de los '90 al nuevo contexto de realidad latinoamericana que puede apreciarse cada vez con mayor claridad.

En el ámbito de la investigación histórica se produce una aceptación cada vez mayor, aunque todavía con marcadas resistencias, de la historia oral en las instituciones académicas, públicas y privadas. El rescate de la memoria histórica dio y sigue dando impulso al trabajo de diversos grupos en la indagación acerca de procesos y acontecimientos, pero también de todo un conjunto de significados que daban ahora la palabra a aquellos que tradicionalmente habían quedado fuera de la historiografía oficial. El protagonismo de los trabajadores y el pueblo ya no puede dejarse de lado.

La Historia Oral ha intentado no sólo el rescate de la memoria de sectores antes marginados en su protagonismo, sino también, el crecimiento de los niveles de conciencia de aquellos como protagonistas de esta historia, y de una realidad que puede ser modificada.

Las contribuciones de la Historia Oral no se limitan al plano metodológico, teniendo en cuenta la larga tradición de preponderancia de la fuente escrita como única realmente “objetiva”. En tanto contribuye a la toma de conciencia, alimenta el surgimiento de nuevos puntos de vista, nuevos debates $\mathrm{y}$, en consecuencia, la posibilidad de un enriquecimiento mucho mayor del conocimiento histórico.

La utilización de testimonios orales para reconstruir el pasado es un recurso tan antiguo como la Historia misma. La Historia Oral en cambio, ya sea que la consideremos como una especialidad dentro del campo historiográfico o como una técnica específica de investigación contemporánea al servicio de varias disciplinas, es un producto del siglo XX que enriqueció sustancialmente el conocimiento de la historia contemporánea. Finalizada la II Guerra Mundial, su emergencia en América y Europa y su posterior desarrollo hasta el presente, obedece a diversas motivaciones y reflexiones acaecidas dentro y fuera del campo académico historiográfico.

La historia oral y la tradición oral sirven de fundamento para reescribir la historia, pero también para combatir las injusticias del pasado. Pueblos que fueron conquistados o colonizados, en el presente recurren a su tradición oral y rescatan su memoria para reclamar derechos territoriales, lingüísticos, o para recuperar una identidad cultural propia. Supervivientes de la lucha en contra de regímenes militares u opresivos, cuestionan hoy la historia oficial con sus memorias subterráneas y reclaman el reconocimiento social y el castigo legal de los responsables de violar los derechos humanos. Aunque en modo menos dramático, la gente común exige respeto para sus memorias y tradiciones. Las investigaciones basadas en historia oral y, en ocasiones, los propios historiadores orales, intervienen en el 
marco jurídico-legal en tanto la memoria y la tradición oral constituyen la evidencia que sustenta las demandas de restitución de los pueblos, ya sea de tierras o de dignidad.

Bien se trate de una revalorización de las fuentes orales frente al imperio de "lo escrito”, del logro de una comunicación más fluida entre historiadores y otros científicos sociales o de la apuesta por una historia más democrática, lo cierto es que lo que surgió como un movimiento de renovación historiográfica y aún de compromiso político es hoy asumido como una especialidad reconocida mundialmente que nos exige una mayor reflexión y labor interdisciplinaria, a la vez que supone nuevos desafíos en el ejercicio de la actividad investigativa, la docencia y la acción comunitaria. Por supuesto lo que debería quedar claro es que las fuentes orales no se limitan únicamente a las entrevistas; por el contrario, anécdotas, canciones, cuentos, folklore, poemas, y un sinfín de formas de transmisión oral son recursos para hacer historia oral.

En general, hemos considerado a la historia como algo profundamente ligado a las fuentes escritas. Esta noción derivada de la visión rankeana (y considerada científica) tiene algo que ver, pero no mucho, con la historia de los pueblos. Los irlandeses tenían sus bardos, los griegos sus tragedias, la oralidad de los incas; todas fueron formas de transmitir la historia. Esta tiene varias funciones: una es la legitimación de un tipo de sociedad determinado; otra es el de la memoria y la transmisión de experiencia, digamos las lecciones del pasado; una última, es la de la constitución de un grupo social a través de la creación de una historia compartida que define identidades colectivas. Así, la historia oral se convertía en la base material necesaria del sentido común y de las estructuras de sentimiento imprescindibles tanto para la dominación como para la liberación del oprimido. En este sentido, la oralidad es la forma más antigua de transmisión del conocimiento histórico.

Sin embargo, no toda cuestión oral es historia oral. Existen múltiples formas de testimonios, que son válidos y útiles, pero que no son historia oral. La labor de entrevista que hace un periodista es oralidad; el trabajo de antropología cultural también lo es; y ni hablar del análisis lingüístico y del discurso. En el caso de la historia oral sus pautas distintivas tienen que ver sobre todo con el hecho de que a través de la oralidad se trata de disparar la memoria para construir una fuente que nos lleve a lograr una forma más completa de comprensión del proceso social.

Si la historia es el ser humano, en sociedad y a través del tiempo, entonces la historia oral provee una fuente al investigador para aprehender tanto la subjetividad de una época, como para percibir una serie de datos que de otra manera no han quedado registrados. Digamos, el testimonio (más allá de su belleza o cualidad emocionante) tiene sentido para el 
historiador mucho más allá de su construcción como discurso, como narración, o como imaginario. Su sentido lo da (o no) el que provee una ventana particular para mejorar nuestra comprensión de una sociedad determinada. Así, el historiador oral debe utilizar no sólo las técnicas del entrevistador sino sobre todo las del historiador, tomando todos los recaudos necesarios tanto al interrogar la fuente como al construir una explicación a partir de ella. Si no hay explicación, si no hay proceso, si el uso de la oralidad no sirve para explicar el proceso histórico, entonces el análisis puede ser válido y hermoso pero no es historia oral.

Por otro lado, y debemos aclararlo, de ninguna manera es la historia oral la historia de "los sin voz". Como toda historia, es una construcción del historiador con los protagonistas. Lo que sí permite, es acceder a sectores no dominantes de maneras innovadoras. O sea, sino fuera por la historia oral en general todo lo que podemos hacer es ver a los oprimidos a través de las fuentes gestadas por los opresores.

De todas maneras, yo no creo ser un historiador oral, creo ser un historiador. Sólo el mal historiador usa parte de sus fuentes disponibles; yo trato de recurrir a todas las posibles. De ahí que cuando encaré el tema de la actividad obrera ante la dictadura argentina de 1976 o el de la guerrilla del PRT-ERP conseguí mucha información escrita, pero sabía que lo cualitativo, lo subjetivo y también una cantidad importante de datos no se podían obtener de otra forma que no fuera de la memoria de los protagonistas.

Para algunos la historia oral es una construcción, una narrativa, mientras que para otros es una forma de aproximación a los sectores sociales "sin historia”; en algunos casos es considerada como una metodología de investigación mientras que en otros es vista como una rama de la Historia equiparable a la historia social o económica. Para amplios sectores profesionales la historia oral, por su subjetividad, es una mera construcción literaria, mientras que para quienes la practican ha significado una profunda renovación intelectual. Además de lo dicotómico (en apariencia) de estas posturas, las mismas formas de “hacer” historia oral varían ampliamente entre los que se dedican a ella. Más allá de que simpaticemos más con algunas que con otras posturas, lo que nos parece importante es que la oralidad obliga al diálogo entre disciplinas cuyas fronteras eran tenidas como estrictas, y asimismo nos fuerza a confrontar con lo que es el sujeto social por excelencia de toda ciencia social: el ser humano.

Por todo lo anterior, y quizás debido a su heterogeneidad, la Historia Oral ha sido, y pretende seguir siendo, producto de un movimiento de cambio progresista en las ciencias sociales centrado en el rescate de la memoria colectiva social e individual. En este sentido, se apuesta a contribuir en alguna medida a una “formación” que incida en el futuro y desde los diversos ámbitos posibles a perfilar una sociedad más democrática, más plural y más justa. La 
utilización de testimonios orales para reconstruir el pasado es un recurso tan antiguo como la historia misma. La historia oral en cambio, ya sea que la consideremos como una especialidad dentro del campo historiográfico o como una técnica específica de investigación contemporánea al servicio de varias disciplinas, es un producto del siglo XX que enriqueció sustancialmente el conocimiento de la Historia contemporánea.

La Historia Oral tiene una larga tradición en América Latina que se remonta, particularmente, a la creación en 1956 del Archivo Sonoro del Instituto Nacional de Antropología e Historia (INAH) de México; proyecto que sin duda establecía los cimientos para el desarrollo de la historia oral y sería el antecedente indiscutible del Archivo de la Palabra que el propio INAH estableció en 1972. Fue ese archivo el que rescató, en forma más completa, la memoria de la Revolución Mexicana a través de los testimonios de sus sobrevivientes. Y fue gracias a estos testimonios que la historia de la primera revolución del siglo XX se pudo complejizar alejándose de la hagiografía tan grata a la ideología oficial del PRI mexicano. Asimismo, podemos destacar el valor del trabajo que se ha realizado en Brasil, fundamentalmente partiendo del esfuerzo del programa de historia oral CPDOC en la Fundación Getulio Vargas sin dejar de lado los importantes desarrollos en toda la década de 1980 en países como Venezuela, Guatemala, Nicaragua, Cuba, Perú, y Puerto Rico. Reflejo de este desarrollo fue el Primer Encuentro de Historiadores Orales de América Latina y España organizado en México en 1988.

Pero todo lo anterior, tanto el desarrollo de la historia oral en América Latina como el volver a discutir "la esencia” de nuestra disciplina, lleva a repensar lo que señaló Okun Udet Uya hace ya tantos años. Para los historiadores nigerianos no hay diferencia entre fuentes orales y escritas, por lo que no puede haber historia oral como disciplina ni como método. ¿Y en América Latina? Es evidente que hay una cantidad cada vez más numerosa de practicantes de la historia oral. En cierta forma esto se debe a las necesidades del presente: o sea a que las prácticas y preguntas de la historia siempre parten de la realidad actual para examinar el pasado con vistas a generar lecciones para el futuro. Que hayan practicantes e instituciones de historia oral conlleva a la pregunta: ¿Existe una historia oral latinoamericana? La “esencia” de la historia oral como "latinoamericana" es por lo menos discutible. O mejor dicho, es tan discutible como lo es la existencia misma de América Latina como proceso histórico y social único y homogéneo. En realidad, y sin ánimo de meterme en una discusión más compleja, profunda y con una larguísima tradición, lo latinoamericano existe en contraposición a lo europeo y lo norteamericano. Como tal los elementos unificadores provienen del colonialismo y del imperialismo. Estos no son solamente conceptos teóricos o políticos, sino más bien 
intentan definir una relación de opresión realmente existente. Por eso las posibilidades de una historia comparativa entre los procesos de la historia de la potencia imperial y la de los pueblos oprimidos siempre han sido complejas y dificultosas. No es imposible, pero si difícil. Es lógico pensar que si bien la historia latinoamericana es historia, que también tiene su esencia particular derivada de esta relación histórica. Como tal, y como subrama de la historia, la historia oral, por cuanto su eje central es la subjetividad, también debería tener una esencia específica latinoamericana derivada de ese proceso histórico.

Es por eso que las prácticas de la historia oral tienen, necesariamente, que ser distintas en América Latina que en otros lugares. Aun en el caso de sociedades fuertemente marcadas por el coloniaje y el imperialismo, como África o Asia, su especificidad también le da características propias al quehacer histórico y por ende a la historia oral. Mi colega y amigo mexicano Gerardo Necoechea señala que "en materia de técnica y método no hay nada que distinga a los historiadores orales latinoamericanos de sus colegas en otras latitudes”. Yo no coincido. Es notable como los manuales de historia oral hechos por colegas de otras latitudes tienen escasa utilidad, por lo menos en Argentina, ya que se basan en prácticas y esencias provenientes de estudiar la historia de países de primer mundo.

En el caso argentino los problemas de hacer historia oral están fuertemente ligados al tema represión y regímenes dictatoriales. El pedir la autorización al entrevistado automáticamente implica entrar en el cono de dudas sobre qué se va a hacer con la entrevista. La autocensura de ambas partes, como técnicas de supervivencia frente a una represión salvaje, marca fuertemente los testimonios, la memoria y la subjetividad. Las técnicas para evocar la memoria o para lograr respuestas no son (y tampoco pueden ser) las mismas que en sociedades con niveles represivos más bajos. Asimismo, la posibilidad de que lo que se declara en una entrevista tenga usos no imaginados por el historiador es un problema ético y práctico que debe ser contemplado y que no figura en ningún manual hecho por europeos o norteamericanos. En mi caso, he sido citado en tres juicios (y por suerte nunca convocado) por fiscales que deseaban utilizar mis entrevistas como prueba de los delitos de lesa humanidad por parte de antiguos guerrilleros. ¿Qué hacer en estos casos? ¿Qué hacer frente a la posibilidad de que el entrevistado otorgó información en confianza sin considerar las posibles consecuencias? Si el entrevistado te cuenta cómo ejecutó a alguien ¿qué hace el historiador? ¿Modifica el testimonio borrando esa parte o lo preserva exponiendo al entrevistado a las consecuencias? Luego, ¿el testimonio se preserva, se publica, se esconde? Los nombres de los entrevistados ¿̇son públicos o debemos utilizar seudónimos? El uso que hacemos de la entrevista se guía por ¿qué criterios? ¿Cómo inciden cuestiones socioculturales 
de género, raza y clase en la construcción de los testimonios? ¿Cómo incide la subjetividad propia del entrevistador, por ejemplo, cuando se entrevista a una persona perteneciente a los pueblos originarios? Y ni hablar de prejuicios, percepciones, o relaciones de deferencia. Una vez más, el hecho de que Ronald Grele, Paul Thompson, Daniel Bertaux, Philippe Joutard y tantos otros no consideren estas cuestiones en sus interesantes y bien escritas guías sobre historia oral implica que nunca jamás tuvieron que enfrentarse a estos problemas.

Ni hablar de otros problemas derivados de la realidad social y de los estados en los que se desenvuelven. Yo miro archivos europeos o norteamericanos con profunda envidia. Se encuentran bien cuidados, organizados, y mantenidos. Lo cual implica que hay dineros y que el Estado y sus sectores dominantes valoran la memoria histórica como lugar de construcción de una hegemonía y un consenso determinados. Lo mismo puedo decir de archivos en México o en Brasil. No es lo mismo en el caso argentino. Una pregunta constante para cualquier historiador oral argentino es: ¿las entrevistas deben ser ubicadas en archivos accesibles al público? ¿Eso qué significa y qué implica? Además, en sociedades donde la corrupción permea al Estado ¿cómo hacer para preservar esa memoria? ¿Cómo hacer para que los archivos no sean vendidos al exterior, o sean destruidos, o peor aun no sean vendidos simplemente como papel descartado y por peso? Los archivos laborales del Ministerio de Trabajo en Argentina se queman cada 10 años por que "no hay donde guardarlos” (y, diría yo, porque la historia obrera no es algo que nuestra clase dominante quiera preservar).

En síntesis, ética, política, esencia y por ende prácticas del historiador se derivan de la realidad en la que se ejerce la profesión. Así como las preguntas y respuestas nos las sugieren el medio social en el que nos desenvolvemos, también las características específicas de nuestro quehacer se ven marcadas y determinadas. Lo anterior obliga a plantearse una vez más aquellos temas tan importantes para muchos de mis profesores: ¿qué es la historia?, ¿historia para qué y para quién?, la ética del historiador. En estos temas, la historia oral es fundamental porque evidencia la importancia de los mismos, por cuanto no son meramente un ejercicio intelectual sino que se imponen debido a las prácticas mismas que surgen de la esencia de la historia oral latinoamericana.

Y esto último lleva a un tema donde Gerardo Necoechea tiene muchísima razón (y no se equivoca). Si bien yo soy de la opinión que la historia oral en sí misma no es subversiva ni democratizadora, ya que estas características surgen del uso que le da el historiador, también debo reconocer una especificidad latinoamericana. Gerardo señala que "nos interesan sujetos, temas y problemas que por lo general quedan fuera de las historias convencionales e incluso fuera de los repositorios documentales”. Absolutamente cierto. La historia oral en América 
Latina tiende a rescatar y a poner en el centro de la historia a personas, a las grandes masas, cuya contribución al proceso histórico ha sido ignorado o dejado de lado por la historia oficial. Como tal la historia oral tiende a ser la "historia de los sin voz" (en el sentido que no quedan registrados sus sentires en los documentos y archivos excepto en formas muy secundarias). Esta característica obliga al historiador oral latinoamericano no sólo a regresar al ser humano como sujeto y protagonista de la historia, sino también lo obliga a concientizarse de que el oficio del historiador es una tarea colectiva entre el técnico (historiador) y el/los sujetos. En el diálogo entre ambos (al igual de lo que debería ser el diálogo constante con un documento escrito) el historiador cambia, se modifica, y su historia se torna más rica, más compleja. Al incorporar la subjetividad como materia central al proceso histórico el historiador se ve obligado a democratizar sus prácticas y su esencia, en el sentido de que la historia una vez más se guía por el gobierno del demos. Y no sólo democratizamos la producción (de hecho sin esto no se puede hacer historia oral), sino que marcamos un elemento particular que hace a la esencia de la historia oral y no sólo a su práctica. La esencia democratizadora se nutre, además, de ese demos y por ende si el demos se ha forjado en procesos históricos latinoamericanos esa esencia no puede ser la misma que la de otras latitudes y otros procesos históricos.

Claro, esto no significa que toda historia oral sea "buena”. Una colega argentina insiste que “cualquiera puede hacer historia oral” y solo hace falta atreverse. No es cierto. Un proyecto de historia oral tiene reglas, criterios y su propia cientificidad. No cualquier entrevista es historia oral, sino cualquier periodista televisivo que entrevista gente sería un historiador oral. Lo que si es cierto es que la historia oral cuestiona fuertemente los límites de gremio feudal establecidos por la academia por cuanto reconoce al individuo común en protagonista de su propia historia.

En síntesis, la práctica de la historia oral nos obliga a plantear temas centrales a la formación del historiador, que fueron moneda corriente en las discusiones de la profesión hace ya medio siglo: Historia ¿para qué? y ¿para quién?; historia y su cientificidad; y la ética del historiador.

Mi práctica como historiador me obliga a recurrir a fuentes orales además de fuentes no orales ya que mi objetivo es comprender los procesos humanos en la esperanza de contribuir a cambiar y mejorar el mundo. En esto soy muy ambicioso: no hago historia para los colegas, la hago para el común de la gente. Por eso siento que me gusta la historia, no los historiadores. Así mi historia es militante y académica o sea científica. No veo contradicción entre ambas. Y tengo en claro que hay historia militante buena y mala, al igual que la historia 
academicista puede ser buena o mala. Ambas son políticas y ninguna es neutral. Mi ética es que trato de ser fiel a mi ciencia, a los objetivos de una historia que le sea útil a la gente, y a la responsabilidad social del historiador. En esto no pierdo de vista que los protagonistas de mi historia, como hacedores y como consumidores, son la gente común. Esto me lo impuso la historia oral que me obligó a enfrentarme y a responder a las contradicciones actuales en el quehacer del historiador retomando los problemas y los principios que mis profesores me plantearon hace ya cuarenta años.

\section{ESSÊNCIA E PRÁTICA DA HISTÓRIA ORAL}

\section{Resumo}

Este artigo/palestra discute a relação entre história, história oral, e a história do presente. Ele estabelece que a delimitação entre elas não é fixa, mas estão articuladas de maneira que as suas fronteiras se misturam. Além disso, no momento de apresentar a história oral como um sub-ramo da ciência histórica, discute-se se as particularidades latino-américanas podem significar que existe uma história oral propriamente "latinoaméricana".

Palavras-chave: História. Oralidade. América Latina. Práticas da história.

\section{ESSENCE AND PRACTICE OF ORAL HISTORY}

\section{Abstract}

This article/lecture discusses the relationship among history, oral history, and history of today. It states that the cleavage among them is not fixed but they integrate each other to the point that their boundaries are blurred. Moreover, since the moment that oral history is presented as a historical science's sub-branch; it is discussed whether the Latin American characteristics can mean the existence of a specifically "Latin American" oral history.

Keywords: History. Orality. Latin America. History practices.

\section{Referências}

CARR, E.H. ¿Qué es la historia? Barcelona: Seix Barral, 1981.

FEBVRE, Lucien. Combates por la historia. Barcelona: Ariel Quincenal, 1974.

LOEWEN, James K. Lies my Teacher Told Me. New York: Simon and Schuster, 1996, p. 239-241.

Recebido em: 23/03/2012

Aprovado em: 20/04/2012 